\title{
A comparative genomics approach identifies a PPR-DYW protein that is essential for C-to-U editing of the Arabidopsis chloroplast accD transcript
}

\author{
JOHN C. ROBBINS, ${ }^{1}$ WADE P. HELLER, ${ }^{1}$ and MAUREEN R. HANSON \\ Department of Molecular Biology and Genetics, Cornell University, Ithaca, New York 14853, USA
}

\begin{abstract}
Several nuclear-encoded proteins containing pentatricopeptide repeat (PPR) motifs have previously been identified to be transfactors essential for particular chloroplast RNA editing events through analysis of mutants affected in chloroplast biogenesis or function. Other PPR genes are known to encode proteins involved in other aspects of organelle RNA metabolism. A function has not been assigned to most members of the large plant PPR gene family. Arabidopsis and rice each contain over 400 PPR genes, of which about a fifth exhibit a C-terminal DYW domain. We describe here a comparative genomics approach that will facilitate identification of the role of RNA-binding proteins in organelle RNA metabolism. We have implemented this strategy to identify an Arabidopsis nuclear-encoded gene RARE1 that is required for editing of the chloroplast accD transcript. RARE1 carries 15 PPR motifs, an E/E+ and a DYW domain, whereas previously reported editing factors CRR4, CRR21, and CLB19 lack a DYW domain. The acc $D$ gene encodes the $\beta$ carboxyltransferase subunit of acetyl coA carboxylase, which catalyzes the first step in fatty acid biosynthesis in chloroplasts. Despite a lack of accD C794 editing and lack of restoration of an evolutionarily conserved leucine residue in the $\beta$ carboxyltransferase protein, rare1 mutants are unexpectedly robust and reproduce under growth room conditions. Previously the serine-to-leucine alteration caused by editing was deemed essential in the light of the finding that a recombinantly expressed "unedited" form of the pea acetyl coA carboxylase was catalytically inactive.
\end{abstract}

Keywords: chloroplast; RNA editing; accD; RARE1; pentatricopeptide; trans-factor

\section{INTRODUCTION}

Vascular plant organelle transcripts undergo C-to-U RNA editing (for review, see Hanson et al. 1996; Bock 2000; Tillich et al. 2005; Shikanai 2006). In Arabidopsis, 34 editing events are known to occur in chloroplast transcripts (Tillich et al. 2005; Chateigner-Boutin and Small 2007), while 508 Cs are known to be modified to Us in Arabidopsis mitochondria (Bentolila et al. 2008). The amino acid encoded by edited transcripts often differs from the one predicted from unedited transcripts, usually resulting in increased evolutionary conservation of the amino acid sequence from the one predicted from genomic sequence (Gualberto et al. 1989), although start and stop codons in organelle transcripts are also sometimes created by C-to- $\mathrm{U}$

\footnotetext{
${ }^{1}$ These authors contributed equally to this work.

Reprint requests to: Maureen R. Hanson, Department of Molecular Biology and Genetics, Cornell University, Biotechnology Building, Ithaca, NY 14853, USA; e-mail: mrh5@cornell.edu; fax: (607) 255-6249.

Article published online ahead of print. Article and publication date are at http://www.rnajournal.org/cgi/doi/10.1261/rna.1533909.
}

editing (Wintz and Hanson 1991; Kudla et al. 1992). The residues modified by RNA editing are often important for the three-dimensional structure of the protein (Yura and Go 2008). RNA editing appears to be a mechanism to correct defective organelle genes at the transcript level.

The suite of particular C-to- $\mathrm{U}$ editing events varies from one plant species to another, even though RNA editing probably arose in an ancestor common to the land plants (Tillich et al. 2006). Between divergent species, such as between dicots and monocots, RNA editing $\mathrm{C}$ targets vary considerably. In species that do not contain a particular C-target of editing, a $\mathrm{T}$ is almost always genomically encoded, resulting in the equivalent of a $\mathrm{C}$-to- $\mathrm{U}$ edited transcript. Of the 34 known Arabidopsis chloroplast editing events, 26 do not occur in rice (Table 1; Tsudzuki et al. 2001; ChateignerBoutin and Small 2007). Between two grasses, rice and maize, only eight differences in the $\mathrm{C}$ targets of editing were reported (Corneille et al. 2000). Within three Solanaceous species, there are $11 \mathrm{C}$ targets that are not conserved among tomato, tobacco, and deadly nightshade (Kahlau et al. 2006). No differences in the editing targets in the plastid 
TABLE 1. Differences in editing targets between Arabidopsis and rice

\begin{tabular}{|c|c|c|c|c|}
\hline \multirow[b]{2}{*}{ Gene } & \multicolumn{2}{|c|}{ Arabidopsis } & \multicolumn{2}{|c|}{ Rice } \\
\hline & $\begin{array}{c}\text { Edited } \\
\text { nucleotide }\end{array}$ & $\begin{array}{l}\Delta \text { Amino } \\
\text { acid }\end{array}$ & $\begin{array}{c}\text { Edited } \\
\text { nucleotide }\end{array}$ & $\begin{array}{c}\Delta \text { Amino } \\
\text { acid }\end{array}$ \\
\hline \multirow[t]{2}{*}{$a c c D$} & C794 & $\mathrm{S} 265 \rightarrow \mathrm{L}$ & $N / A^{c}$ & $N / A$ \\
\hline & $\mathrm{C} 1568^{\mathrm{b}}$ & 3'UTR & $N / A^{c}$ & N/A \\
\hline $\operatorname{atp} A$ & $\mathrm{~T}$ & L383 & C1148 & $\mathrm{S} 383 \rightarrow \mathrm{L}$ \\
\hline $\operatorname{atpF}$ & C92 & $\mathrm{P} 31 \rightarrow \mathrm{L}$ & $\mathrm{T}$ & L31 \\
\hline clpP & C559 & $\mathrm{H} 187 \rightarrow \mathrm{Y}$ & $\mathrm{T}$ & Y187 \\
\hline \multirow[t]{2}{*}{ matK } & C640 & $\mathrm{H} 214 \rightarrow \mathrm{Y}$ & $\mathrm{T}$ & Y236 \\
\hline & $\mathrm{T}$ & Y415 & $\mathrm{C} 1351^{\mathrm{a}}$ & $\mathrm{H} 420 \rightarrow \mathrm{Y}$ \\
\hline \multirow[t]{2}{*}{$n d h A$} & $\mathrm{~T}$ & L159 & C473 & $\mathrm{S} 158 \rightarrow \mathrm{L}$ \\
\hline & $\mathrm{T}$ & F355 & C1070 & $\mathrm{S} 357 \rightarrow \mathrm{F}$ \\
\hline \multirow[t]{12}{*}{$n d h B$} & C149 & $\mathrm{S} 50 \rightarrow \mathrm{L}$ & $\mathrm{T}$ & L50 \\
\hline & C467 & $\mathrm{P} 156 \rightarrow \mathrm{L}$ & C467 & $\mathrm{P} 156 \rightarrow \mathrm{L}$ \\
\hline & C586 & $\mathrm{H} 196 \rightarrow \mathrm{Y}$ & C586 & $\mathrm{H} 196 \rightarrow \mathrm{Y}$ \\
\hline & $C^{N E}$ & S204 & C611 & $\mathrm{S} 2 \mathrm{O} 4 \rightarrow \mathrm{L}$ \\
\hline & $\mathrm{T}$ & F235 & C704 & $\mathrm{S} 235 \rightarrow \mathrm{F}$ \\
\hline & $\mathrm{T}$ & L246 & C737 & $\mathrm{P} 246 \rightarrow \mathrm{L}$ \\
\hline & C746 & $\mathrm{S} 249 \rightarrow \mathrm{F}$ & $\mathrm{T}$ & F249 \\
\hline & C830 & $\mathrm{S} 277 \rightarrow \mathrm{L}$ & C830 & $\mathrm{S} 277 \rightarrow \mathrm{L}$ \\
\hline & C836 & $\mathrm{S} 279 \rightarrow \mathrm{L}$ & C836 & $\mathrm{S} 279 \rightarrow \mathrm{L}$ \\
\hline & C872 & $\mathrm{S} 291 \rightarrow \mathrm{L}$ & $C^{N E}$ & S291 \\
\hline & C1255 & $\mathrm{H} 419 \rightarrow \mathrm{Y}$ & $\mathrm{T}$ & Y419 \\
\hline & C1481 & $\mathrm{P} 494 \rightarrow \mathrm{L}$ & C1481 & $\mathrm{P} 494 \rightarrow \mathrm{L}$ \\
\hline \multirow[t]{5}{*}{$n d h D$} & $\mathrm{C} 2$ & $\mathrm{~T} 1 \rightarrow \mathrm{M}$ & $\mathrm{T}$ & M1 \\
\hline & C383 & $\mathrm{S} 128 \rightarrow \mathrm{L}$ & $\mathrm{T}$ & L128 \\
\hline & C674 & $\mathrm{S} 225 \rightarrow \mathrm{L}$ & $\mathrm{T}$ & L225 \\
\hline & C878 & $\mathrm{S} 293 \rightarrow \mathrm{L}$ & C878 & $\mathrm{S} 293 \rightarrow \mathrm{L}$ \\
\hline & C887 & $\mathrm{P} 296 \rightarrow \mathrm{L}$ & $\mathrm{T}$ & L296 \\
\hline \multirow[t]{2}{*}{$n d h F$} & $\mathrm{~T}$ & L21 & C62 & $\mathrm{S} 21 \rightarrow \mathrm{L}$ \\
\hline & C290 & $\mathrm{S} 97 \rightarrow \mathrm{L}$ & $\mathrm{T}$ & L97 \\
\hline \multirow[t]{3}{*}{$n d h G$} & $\mathrm{~T}$ & 5'UTR & $C(-10)^{d}$ & 5'UTR \\
\hline & C50 & $\mathrm{S} 17 \rightarrow \mathrm{F}$ & $\mathrm{T}$ & $\mathrm{F} 17$ \\
\hline & $\mathrm{T}$ & L116 & $\mathrm{C} 347^{\mathrm{a}}$ & $\mathrm{P} 116 \rightarrow \mathrm{L}$ \\
\hline petL & $\mathrm{C} 5$ & $\mathrm{P} 2 \rightarrow \mathrm{L}$ & $\mathrm{T}$ & L2 \\
\hline$p s b E$ & C214 & $\mathrm{P} 72 \rightarrow \mathrm{S}$ & $\mathrm{T}$ & S72 \\
\hline$p s b F$ & C77 & $\mathrm{S} 26 \rightarrow \mathrm{F}$ & $\mathrm{T}$ & F26 \\
\hline$p s b Z$ & C50 & $\mathrm{S} 17 \rightarrow \mathrm{L}$ & $\mathrm{C}^{\mathrm{NE}}$ & S17 \\
\hline$r p / 2$ & $\mathrm{~T}$ & M1 & $\mathrm{C} 2$ & $\mathrm{~T} 1 \rightarrow \mathrm{M}$ \\
\hline rpl23 & C89 & $\mathrm{S} 30 \rightarrow \mathrm{L}$ & $\mathrm{T}$ & F30 \\
\hline rрoA & C200 & $\mathrm{S} 67 \rightarrow \mathrm{F}$ & $\mathrm{T}$ & F67 \\
\hline \multirow[t]{5}{*}{ rров } & C338 & $\mathrm{S} 113 \rightarrow \mathrm{L}$ & $\mathrm{T}$ & F111 \\
\hline & $\mathrm{T}$ & L158 & C467 & $\mathrm{S} 156 \rightarrow \mathrm{L}$ \\
\hline & C551 & $\mathrm{S} 184 \rightarrow \mathrm{L}$ & C545 & $\mathrm{S} 182 \rightarrow \mathrm{L}$ \\
\hline & $\mathrm{T}$ & L189 & C560 & $\mathrm{S} 187 \rightarrow \mathrm{L}$ \\
\hline & C2432 & $\mathrm{S} 811 \rightarrow \mathrm{L}$ & $\mathrm{T}$ & L811 \\
\hline rpoC1 & C488 & $\mathrm{S} 163 \rightarrow \mathrm{L}$ & $\mathrm{T}$ & L163 \\
\hline rps8 & $\mathrm{T}$ & L61 & C182 & $\mathrm{S} 61 \mathrm{~S} \rightarrow \mathrm{L}$ \\
\hline rps12 & $C(\text { i1 58) })^{\mathrm{e}}$ & intron & $\mathrm{C}(\text { i1 54 })^{\mathrm{NE}}$ & intron \\
\hline \multirow[t]{2}{*}{ rps14 } & C80 & $\mathrm{S} 27 \rightarrow \mathrm{L}$ & $\mathrm{C} 80$ & $\mathrm{~S} 27 \rightarrow \mathrm{L}$ \\
\hline & C149 & $\mathrm{P} 50 \rightarrow \mathrm{L}$ & $\mathrm{T}$ & $\mathrm{L} 47$ \\
\hline$y c f 3$ & $\mathrm{~T}$ & M20 & C185 & $\mathrm{T} 62 \rightarrow \mathrm{M}$ \\
\hline
\end{tabular}

Data derived from (Tsudzuki et al. 2001; Chateigner-Boutin and Small 2007); N/A indicates not applicable; NE indicates not edited. ${ }^{a}$ Actual editing has not been assayed; editing is assumed by orthology to maize (Tillich et al. 2006)

'Position in 3' UTR from A of ATG.

${ }^{\mathrm{C}}$ Gene not present in rice.

'Position in 5' UTR from A of ATG.

${ }^{\mathrm{d}}$ Position within intron 1, where $i 11$ is first nucleotide after splice site.
(Tillich et al. 2005) or mitochondrion (Bentolila et al. 2008) have been detected in ecotypes of Arabidopsis thaliana, although variation in the efficiency of editing of particular mitochondrial Cs has been observed (Bentolila et al. 2005; Zehrmann et al. 2008).

The cis-elements required for RNA editing of particular Cs in chloroplasts and mitochondria are typically within about 30 nucleotides (nt) $5^{\prime}$ and $10 \mathrm{nt} 3^{\prime}$ of the $\mathrm{C}$ target. Sequences surrounding editing sites have been analyzed either by introduction of altered cis-elements into transgenic tobacco plastids (Chaudhuri and Maliga 1996; Reed et al. 2001), or by assaying RNA variants in chloroplast or mitochondrial extracts competent for editing in vitro (Hirose and Sugiura 2001; van der Merwe et al. 2006; Hayes and Hanson 2007b). High-level expression of an RNA carrying an $r p o B$ editing site or an $n d h F$ editing site led to the development of the "cluster hypothesis" of ciselements and trans-factors (Chateigner-Boutin and Hanson 2002). Transplastomic plants overexpressing the $r p o B$ transcript exhibited reduced editing at four other $C$ targets whose sequences immediately $5^{\prime}$ exhibited some similarity. Likewise, editing extents of two different sites in plants overexpressing the $n d h F$ transcripts were reduced in efficiency. In both cases, there was some sequence similarity immediately $5^{\prime}$ to the $C$ target in the $r p o B$ or $n d h F$ transcripts in the sites whose editing efficiency was reduced (Chateigner-Boutin and Hanson 2002). This finding can best be explained as the presence of trans-factors that are shared among the $r p o B$-related sites or the $n d h F$-related sites. Similar results have been obtained when RNA editing in chloroplast and mitochondrial extracts has been assayed. Addition of excess amounts of one editing substrate results in reduced editing of additional editing substrates exhibiting weak similarity (van der Merwe et al. 2006; Heller et al. 2008).

The involvement of a trans-factor in editing of more than one site suggests how plants may survive the creation of new $\mathrm{C}$ targets for editing. If an organelle genome acquires a T-to- $\mathrm{C}$ mutation that becomes fixed, the plant may not survive if an encoded amino acid altered by the affected codon is important for protein function. However, if a preexisting trans-factor can edit a new site sufficiently to produce at least some functional protein, the plant may be able to survive (Covello and Gray 1993). Selection can then occur either on the cis-elements or the trans-factor(s) in order to improve the efficiency of editing. The higher conservation of a $5^{\prime}$ element to a potential $C$ target in $p s b E$ transcripts in land plants than in those carrying a genomically encoded $\mathrm{T}$ is consistent with selection for a sequence efficiently recognized by a trans-factor (Hayes and Hanson 2008).

Trans-factors required for editing of particular $\mathrm{C}$ targets in chloroplasts have been identified, and all have been pentatricopeptide repeat (PPR)-containing proteins, members of a large gene family in plants (Small and Peeters 2000). The $P$ subclass of PPR proteins carries 35 amino acid repeats, while the PLS family carries "long" 35-36 amino 
acid repeats as well as "short" 31 amino acid repeats. Members of the PLS class also have E and E+ "extended" domains absent from the P class. Some members of the PLS class additionally carry a DYW domain, named for the characteristic final tripeptide (Lurin et al. 2004; SchmitzLinneweber and Small 2008). The first three reported chloroplast trans-factors are all members of the PLS E/E+ class, and all were identified in Arabidopsis mutants with defects in chloroplast function. The first two known chloroplast editing trans-factors, CRR4 and CRR21, were found in Arabidopsis mutants with defective $\mathrm{NAD}(\mathrm{P}) \mathrm{H}$ dehydrogenase (Kotera et al. 2005; Okuda et al. 2007), and each is required for editing of a different $\mathrm{C}$ target in the $n d h D$ transcript. Additionally, an editing factor named CLB19 was identified through analysis of an Arabidopsis chlorophyll-deficient mutant, and is required for editing of $\mathrm{C}$ targets in $r p o A$ and $c l p P$ transcripts (Chateigner-Boutin et al. 2008). The membership of these first three editing factors in the PLS E/E+ subclass lacking a DYW domain was surprising, as phylogenetic considerations suggest that the DYW subclass is associated with the development and retention of chloroplast RNA editing (Salone et al. 2007). However, a PPR-DYW gene has been shown to be required for intergenic processing of a chloroplast transcript (Hashimoto et al. 2003), and there is evidence for function of DYW domains as endoribonucleases (Nakamura and Sugita 2008). While this paper was under review, two reports appeared that described the identification of three PPR-DYW proteins as chloroplast site-specific editing factors (Zhou et al. 2009; Okuda et al. 2009).

To identify additional editing trans-factors, we have developed an alternative approach to forward genetic screens of chloroplast biogenesis mutants. If an editing site is lost by a C-to- $\mathrm{T}$ mutation in the genome, then trans-factors previously recognizing this site will no longer be selectively maintained, allowing for their divergence or loss over evolutionary time. Likewise, if a T-to-C change occurs in one lineage but not another, a trans-factor is likely to evolve to allow efficient editing in that lineage but will not be needed in other lineages.

To design an efficient reverse genetic screen for RNA editing trans-factors, we examined the Arabidopsis genome sequence to identify putative chloroplast-targeted PPR proteins that lack identifiable orthologs in the complete rice sequence. By narrowing our candidate list to those genes whose proteins are predicted to be chloroplast targeted by both the TargetP and Predotar algorithms, we identified a list of eight candidate genes likely to carry out functions in Arabidopsis that are not required in rice chloroplasts. Our analysis of one of these eight Arabidopsis genes encoding PPRs revealed a factor essential for editing of the $a c c D$ transcript, which encodes a subunit of the heteromeric acetyl-CoA carboxylase (ACCase) that is found in plastids of dicots but is not present in the rice and other Gramineae (Konishi et al. 1996).

\section{RESULTS}

\section{Identification of candidate PPR genes affecting Arabidopsis chloroplast RNA metabolism}

Examination of the POGS/Plant RBP RNA-binding protein database (http://plantrbp.uoregon.edu/), which integrates data from Arabidopsis, maize, and rice genome sequencing (Walker et al. 2007), revealed the existence of Arabidopsis models for genes encoding PPR proteins predicted to be targeted to the chloroplast by both the Predotar and TargetP databases (Table 2). Eight such Arabidopsis genes

TABLE 2. Known and candidate genes affecting chloroplast RNA metabolism

\begin{tabular}{|c|c|c|c|c|}
\hline $\begin{array}{l}\text { Arabidopsis } \\
\text { locus }\end{array}$ & $\begin{array}{l}\text { Gene } \\
\text { name }\end{array}$ & $\begin{array}{l}\text { Putative } \\
\text { rice ortholog } \\
\text { exists? }\end{array}$ & $\begin{array}{l}\text { Predotar/targetP } \\
\text { plastid targeted } \\
\text { (one/both/neither) }\end{array}$ & $\begin{array}{c}\text { Location } \\
\text { of RNA } \\
\text { editing event }\end{array}$ \\
\hline At1g05750 & CLB19 & Yes & Both & rpoA C200, clpP C559 \\
\hline At1g11290 & CRR22 & Yes & Both & ndhD C887, ndhB C746, гроB C551 \\
\hline At1g59720 & CRR28 & Yes & Both & nhdB C467, ndhD C878 \\
\hline At1g79080 & & No & Both & \\
\hline At2g45350 & CRR4 & No & Neither & ndhD C2 \\
\hline At3g04760 & & No & Both & \\
\hline At3g26630 & & No & Both & \\
\hline At3g22690 & YS1 & No & Both & rpoB C338 \\
\hline At4g14190 & & No & Both & \\
\hline At5g13270 & RARE1 & No & Both & accD C794 \\
\hline At5g24830 & & No & Both & \\
\hline At5g52850 & & No & Both & \\
\hline At5g55740 & CRR21 & Yes & Both & ndhD C383 \\
\hline
\end{tabular}

Data are derived from the PlantRBP database, Kotera et al. (2005), Okuda et al. (2007), Chateigner-Boutin et al. (2008), Zhou et al. (2009), Okuda et al. (2009), and this paper. C targets are numbered relative to the A of the ATG predicted translation initiation codon, where A $=1$. 
had no obvious orthologs in rice according to PlantRBP, and Reciprocal Best Hit analysis using the Oryza sativa nuclear genome sequence confirmed the absence of putative rice orthologs.

\section{Identification of a candidate editing factor by virus-induced gene silencing}

Preliminary experiments resulted in $<50 \%$ of Arabidopsis bleached seedlings among those we agroinfiltrated with a tobacco rattle virus-induced gene silencing (VIGS) vector containing a phytoene desaturase (PDS) gene sequence (Burch-Smith et al. 2006). We also found that bleached tissue resulting from silencing of PDS exhibited altered RNA editing levels at some Arabidopsis chloroplast sites (Supplemental Fig. S1). Because we needed to identify silenced tissue for our studies, we introduced a GFP sequence into the silencing vector so that we could visually screen for silencing of GFP in transgenic Arabidopsis expressing GFP (Turnage et al. 2002; Burch-Smith et al. 2006). RNA could then be isolated from leaves exhibiting reduced GFP expression to assay RNA editing efficiency.

We introduced sequences from the genes encoding the known editing factors CRR4 and CRR21 into the VIGS vector. Gene-specific sequences were selected from the Complete Arabidopsis Transcriptome MicroArray (CATMA) database (Crowe et al. 2003) gene-sequence tag database.

Following agroinfiltration and visual screening for reduced GFP fluorescence, we assayed editing of chloroplast Cs using a sensitive poisoned primer extension (PPE) assay (Peeters and Hanson 2002; Hayes and Hanson 2007a). As expected, the efficiency of editing of the start codon of $n d h D$ was specifically reduced in plants inoculated with a CRR4-containing VIGS vector, and likewise, editing of the ndhD C383 site was reduced in plants silenced for CRR21 (Fig. 1A). We applied this same strategy to At5g13270 and discovered that it exhibited reduced editing efficiency of the accD C794 site relative to plants that were uninoculated or silenced for CRR4 (Fig. 1B). No other editing defects were detected in the At5g13270-silenced plants.

\section{Phenotype of insertional mutants in At5g13270}

We obtained an Arabidopsis ecotype Columbia line carrying a coding region T-DNA insertion in At5g13270 (WiscDs Lox330H10) from the Arabidopsis Biological Resource Center (Woody et al. 2007). T-DNA line FLAG_424E06, carrying a promoter insertion in At5g13270, was obtained from the FLAGdB collection made by INRA, and GABI-Kat line 167A04, which has an insertion 269 base pairs (bp) downstream from the start codon, was obtained from GABI-Kat II in Germany (Fig. 2).

Segregating populations of WiscDsLox330H10 were genotyped, and wild-type, heterozygous, and homozygous mutant plants were identified. Homozygous plants were vigorous,
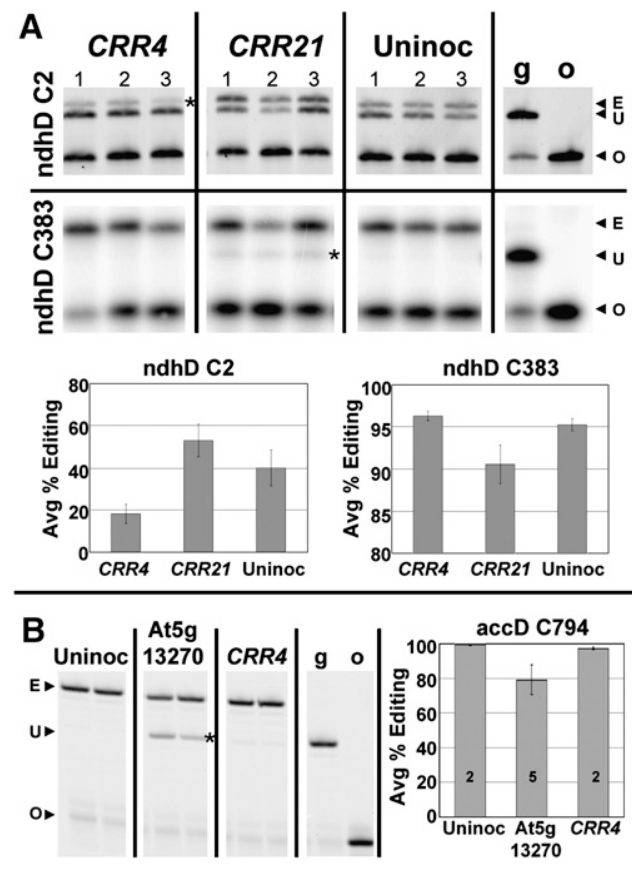

FIGURE 1. VIGS of Arabidopsis genes affects editing of particular C targets. (A) Assays of RNA editing of two targets in $n d h D$ transcripts following inoculation of Arabidopsis plants with gene silencing vectors designed to silence the known editing factor genes CRR4 and CRR21. PPE products for the ndhD C2 and ndhD C383 editing sites from uninoculated leaves and leaves exhibiting GFP cosilencing of CRR4 or CRR21. Extension products are E, edited; U, unedited; and O, oligo; corresponding to 45,42 , and $35 \mathrm{nt}$ for $\mathrm{ndhD} \mathrm{C} 2$, and 41, 35, and $25 \mathrm{nt}$ for ndhD C383, respectively. Bottom panel: bar chart showing average percent editing of $n d h D$ sites from three replicate plants inoculated with the same silencing constructs as in the top panel. Error bars represent one standard deviation from the mean. (B) Assays of RNA editing at accD C794 following inoculation of Arabidopsis plants with vectors designed to silence At5g13270 and CRR4. Top panel: PPE products for the accD 794 site from uninoculated leaves and leaves exhibiting GFP cosilencing. Extension products are E, edited, $34 \mathrm{nt}$; U, unedited, $30 \mathrm{nt}$; and $\mathrm{O}$, oligo, $22 \mathrm{nt}$. Bar chart showing average percent editing of accD C794 from two, five, and two replicate plants, respectively, inoculated with GFP cosilencing constructs as in the top panel. Error bars represent one standard deviation from the mean.

and set seed under our growth room conditions (Fig. 3A). No obvious differences in size, morphology, or number of chloroplasts between homozygous mutants and wild type were detected when autofluorescent mesophyll chloroplasts were examined by confocal microscopy (Fig. 3B).

RNA was prepared from leaves of wild-type, heterozygous, and homozygous WiscDsLox330H10 mutant plants and RNA editing extent was assayed by PPE at all 34 known chloroplast editing sites. The poisoned primer extension assay we used is known to be able to detect edited transcripts representing as little as $1 \%$ of the RNA population (Hayes and Hanson 2007a). All sites exhibited the wild-type extent of RNA editing in the wild-type and heterozygous plants. In the homozygous WiscDsLox33H10 mutants, no editing was detected at accD C794 (Fig. 4A). FLAG_424E06 plants exhibit an editing defect at the accD 


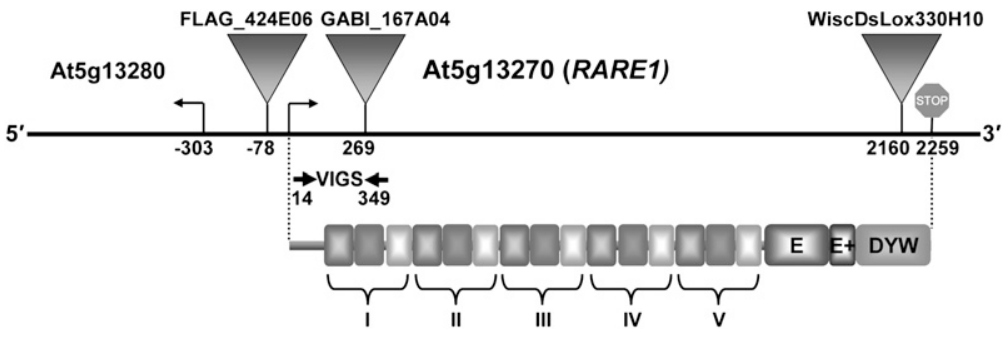

FIGURE 2. Structure of the At5g13270 locus and the predicted RARE1 protein. The locations of T-DNA insertions associated with decreased accD C794 editing are indicated. The 335-nt region of At5g13270 RNA targeted by VIGS is delimited by facing arrows. Depicted below the gene model is the modular organization of the predicted RARE1 protein. Starting at residue 47, five tandem PLS blocks (I-V), of either 101 or 102 residues are shown followed by the E, E+, and DYW domains (Lurin et al. 2004). RARE1 motif coordinates are defined in Supplemental Figure S2. The P, L, and S forms of the PPR motifs are indicated left to right by three different shadings of gray boxes. Figure is drawn to scale. dehydrogenase subunit not needed in nongreen tissues, it is not surprising that expression of both genes in root is very low (Fig. 6).

To determine whether editing of accD C794 occurs in both green and nongreen tissues, PPE was performed on WiscDsLox330H10 RNA isolated from roots, rosette and cauline leaves, and mature flowers of homozygous mutant and wild-type plants. No tissuespecific variation in editing extent was observed and no mutant tissues exhibited any editing of accD C794 (Fig. 7).
C794 site, though partial editing does occur (Fig. 4B). Because the FLAG insertion is in the promoter region, possibly some transcript and protein is produced that allows a low level of editing. GABI_167A04 plants do not edit accD C794 (Fig. 4C). These findings led us to name At5g13270 the first gene required for accD RNA editing (RARE1). Because mutations of RARE1 do not affect editing of the second $C$ target in $a c c D$ (Fig. 4A), it is likely that another gene will be found that is required for editing of $\mathrm{accD}$ C1568.

To determine whether or not the WiscDSLox $330 \mathrm{H} 10$ line expressed the RARE1 RNA despite the T-DNA insertion and complete lack of editing of accD C794, we performed semiquantiative RT-PCR on leaves of wild type and the mutant. Transcripts of At5g13270 were detected in both wild-type and the mutant lines (Fig. 5). Transcripts of At5g13270 were also observed in the FLAG_424E06 line (data not shown).

\section{Expression levels of RARE1 transcripts and extent of editing in different tissues}

Most PPR protein-encoding genes that have been examined are expressed at low levels, though one class of mitochondrial PPR genes are expressed at higher levels (Uyttewaal et al. 2008). To determine expression levels of RARE1 in various tissues, we examined the GENEVESTIGATOR Arabidopsis microarray gene expression database (Zimmermann et al. 2004) (https://www.genevestigator. ethz.ch). We also compared the expression of RARE1 with that of six additional chloroplast editing factors (Fig. 6). Transcripts of all six of these editing factors are expressed at relatively low levels. CLB19 and RARE1 edit transcripts encoding proteins expected to be active in both nongreen and green tissues in the plant, and transcript abundance does not vary much except for a tripling of expression of RARE1 in embryo tissue. Because CRR4, CRR21, CRR22, and CRR28 each edit a transcript encoding a $\mathrm{NAD}(\mathrm{P}) \mathrm{H}$

\section{RARE1 is a PPR-DYW protein required for editing of acc $D$ transcripts}

The protein encoded by At5g13270 contains 15 PPR motifs organized into five PLS blocks, E/E+, and DYW domains (Fig. 2). The location of the three T-DNA insertions within the gene and the sequence utilized for virus-induced gene silencing is also indicated in Figure 2. Taken together, the reduced editing of $a c c D$ transcripts associated with three mutant alleles of RARE1 and in plants inoculated with a VIGS vector reveals the importance of this PPR-DYW protein in editing of a serine to leucine codon in the $\beta$ carboxyltransferase subunit of the heteromeric acetyl-coA carboxylase.

One of the three T-DNA insertion alleles we have analyzed, WiscDsLox330H10, exhibits an insertion within the region encoding the DYW domain. The mutant protein

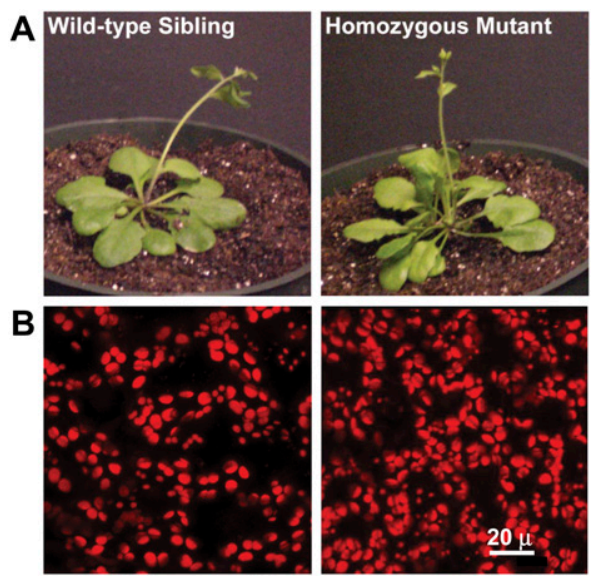

FIGURE 3. A mutant lacking editing of accD C794 exhibits robust growth and chloroplasts of normal appearance. $(A)$ Plant growth phenotype of a wild-type Columbia plant and homozygous mutant WiscDsLox330H10 (B) Confocal microscopy of mesophyll chloroplasts from rosette leaves of wild-type Columbia and the homozygous WiscDsLox330H10 mutant. Images are false-colored red to correspond to chlorophyll autofluorescence. 
predicted from the transcripts we detected (Fig. 5) would contain only the $\mathrm{N}$-terminal portion of the DYW domain, followed by 17 amino acids encoded by the T-DNA insertion (Fig. 2.) While most of the predicted mutant protein, including the PPR motifs, E/E+, and part of the DYW domains, does not differ from wild-type RARE1, it is evidently unable to function in editing of $a c c D$ transcripts either due to a lack of protein stability or a necessity for the entire DYW domain for functionality.

Both the sequence and organization are conserved among all seven editing factors (Kotera et al. 2005; Okuda et al. 2006; Chateigner-Boutin et al. 2008; Zhou et al. 2009; Okuda et al. 2009), especially in the latter part of PLS block 4, PLS block 5, and the C-terminal E/E+ domains (Fig. 8; Supplemental Fig. S2). In contrast, the N-terminal halves are less conserved, as a whole, which is primarily a function of variability in the number of PLS blocks. RARE1 and the other three PPR-DYW editing factors also exhibit high sequence similarity in the DYW domain, but the region bridging the end of the E/E+ domain and the beginning of the DYW domain (the E-DYW bridge: commencing with residue 657 of RARE1) is much less conserved than what is found in other regions of the $\mathrm{C}$ termini (Fig. 8; Supplemental Fig. S2). An alignment of the five PLS blocks with

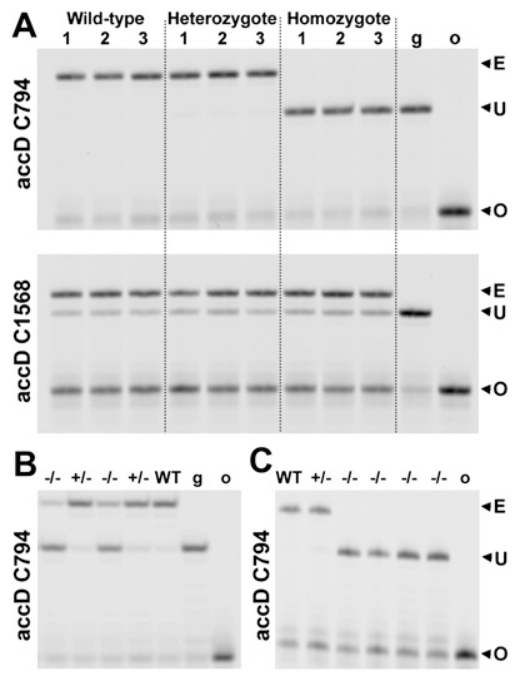

FIGURE 4. Homozygous mutant lines exhibit editing defects in accD C794. RNA assayed in each lane was prepared separately from a single leaf of a different individual plant. $\mathrm{E}, \mathrm{U}$, and $\mathrm{O}$ indicate edited extension product, unedited extension product, and oligonucleotide, respectively, and represent 34,30 , and $22 \mathrm{nt}$ for the C794 site. (A) PPE of RNA from Columbia (wt), heterozygous, and homozygous WiscDsLox $330 \mathrm{H} 10$ plants. The edited and unedited extension products and oligonucleotide for the C1568 site are 33, 31, and $24 \mathrm{nt}$ in size. $(B)$ PPE assay of accD C794 editing in progeny of a heterozygous plant carrying the FLAG_424E06 insertion allele. WT (ecotype WS-4), heterozygotes $(+/-)$ and homozygotes $(-/-)$. Control lanes $g$ and $o$ correspond to genomic DNA template and oligonucleotide only, respectively. (C) PPE assay of accD C794 editing in Columbia (WT), a heterozygote $(+/-)$ and homozygous mutant $(-/-)$ plants carrying the GABI_167A04 insertion allele.

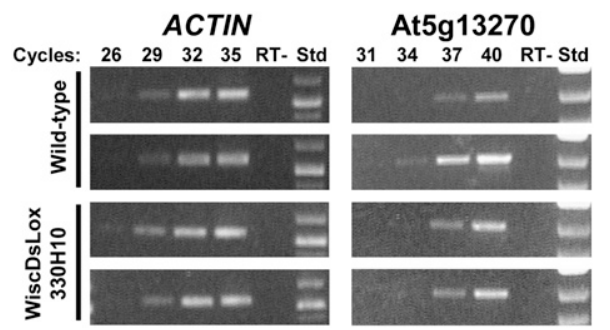

FIGURE 5. Transcripts of At5g13270 are present in both wild-type and WiscDsLox330H10 homozygous mutant plants. Semiquantitative RT-PCR of ACTIN and RARE1 transcripts in two wild-type and two mutant plants. PCR product sizes are $571 \mathrm{bp}$ and $990 \mathrm{bp}$ for ACTIN and RARE1, respectively. Number of PCR cycles is indicated above each lane.

each other and with a highly conserved PPR-related motif in the E domain is shown in Supplemental Figure S3. Further details about the relationships between the PLS blocks in RARE1 are shown in Supplemental Figure S3.

As is the case for nearly all PPR-motif-containing genes ending with a DYW domain, At5g13270 is intronless. Genes exhibiting high similarity to A. thaliana RARE1 can be identified in the genome sequence data for grape and poplar (Supplemental Fig. S4). A cDNA from grape (GenBank accession CB976854) indicates that this species edits $a c c D$ transcripts at the same codon as in A. thaliana. Physicochemical conservation between the three putative orthologous sequences is also quite high (data not shown). Comparison of the RARE1 orthologs indicate a high degree of conservation throughout the protein sequences; however, the region that corresponds to the E-DYW bridge shows a lesser degree of similarity (Supplemental Fig. S4).

The $\mathrm{N}$ terminus of mature RARE1 has not been determined, but TargetP predicts a transit sequence 80 amino acids in length. If cleavage does occur at this location, then it would affect a PPR motif that begins at the 47th amino acid from the $\mathrm{N}$ terminus. A block conserved between the predicted Arabidopsis, grape, and poplar proteins begins at the 21st $\mathrm{N}$-terminal amino acid. Previously, fusion of 100 amino acids of $\mathrm{N}$-terminal sequence of RARE1 with DsRed2 was reported to result in plastid targeting in electroporated tobacco protoplasts (Lurin et al. 2004). Before any information was available about its function, RARE1 by chance was used as a representative DYW protein in assays of four PPR proteins for binding to homoribopolymers, and was observed to bind to polyG, but not to polyA, polyC, polyT nor to single- or doublestranded DNA (Lurin et al. 2004).

\section{DISCUSSION}

We have shown the effectiveness of a novel comparative genomics strategy that takes into consideration the coevolution 


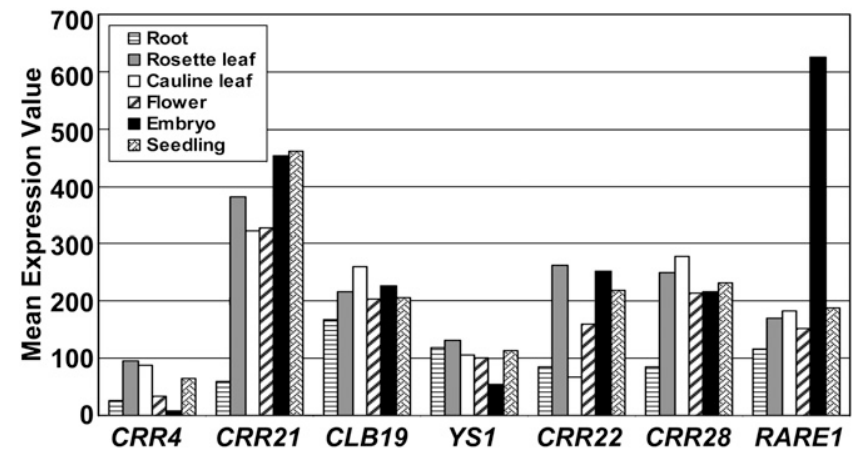

FIGURE 6. Expression levels of the seven known trans-factors of RNA editing according to online microarray data (https://www. genevestigator.ethz.ch). Accession numbers for editing factors are shown in Table 2, except CRR22 (Atlg11290) and CRR28 (At1g59720).

of nuclear-encoded ligands and their corresponding organellar substrates for identification of the function of proteins involved in plant organelle RNA metabolism. Candidate genes affecting species-specific aspects of organelle metabolism can be selected by finding proteins carrying RNAbinding domains that are present in one species but lack identifiable orthologs in a second species. Subsequently, plants silenced or mutated in these genes can be tested for loss of species-specific events affecting transcription, RNA processing, or translation.

We have shown that three mutant alleles of an Arabidopsis nuclear gene affect RNA editing of a chloroplast transcript that is not encoded by the rice genome. Not only does the editing event at accD C794 not occur in the rice genome, but also the $a c c D$ gene itself does not exist in the rice chloroplast genome. Thus, other RNA metabolism events in Arabidopsis that involve the $a c c D$ gene may require additional nuclear genes that are not needed in rice and other Graminae that lack the accD gene. RARE1, the $a c c D$ editing factor gene, was successfully detected among a group of Arabidopsis PPR genes predicted to carry a chloroplast transit sequence and lacking identifiable rice orthologs. Future analysis of the remaining seven Arabidopsis PPR genes in Table 2 could focus on RNA editing sites that occur in Arabidopsis but not rice, as well as other events in RNA metabolism that are specific to Arabidopsis. Furthermore, the converse experiment can be performed to identify the role of RNA-binding proteins in rice genes by identification of rice genes for chloroplast RNA-binding proteins that lack Arabidopsis orthologs.

In other model and crop species for which sufficient genome sequence and mutant collections are available, this strategy can be applied for identification of RNA-binding proteins responsible for $5^{\prime}$ and 3' RNA processing, RNA turnover, intron splicing, and translational activation or repression, in addition to RNA editing events. Because CRR4, one of the four verified chloroplast editing factors listed in Table 1, was not predicted to be targeted to the chloroplast by either Predotar or TargetP, candidate nuclear genes for proteins affecting organelle RNA metabolism should obviously not be eliminated by a lack of predicted organelle targeting until prediction algorithms become more reliable. In fact, CRR4 is an Arabidopsis gene lacking an ortholog in rice and would have been on the list of candidate genes in Table 2 except for the lack of a predicted chloroplast transit sequence. Editing factors CLB19 and CRR21 would also not have been identified as candidates using our strategy because of the presence of putative orthologs in the rice nuclear genome. As rice does not edit the C targets for which CLB19 and CRR21 are required in Arabidopsis, the putative rice orthologs identified bioinformatically are clearly not performing identical functions in the dicot and monocot species. Some RNA metabolism genes will not be readily identified by our strategy in cases where evolution of the ancestral gene has resulted in divergent functions in recognizably similar genes that remain present in distantly related species.

We have identified only one editing event for which the RARE1 protein is required: accD C794. Like CRR4 and CRR21, RARE1 appears to be essential for only one C-to-U modification. Therefore, the cis-elements surrounding accD C794 are unlikely to be present in a cluster of editing sites (Chateigner-Boutin and Hanson 2002) that would crosscompete for RARE1 if one transcript were in excess. We have not observed any strong similarity of the sequences $5^{\prime}$ to accD C794 in close proximity to other C targets of editing in Arabidopsis.

The robustness of the plants that lack the editing required to produce a leucine codon 265 in Arabidopsis $a c c D$ transcripts is surprising, as this residue was thought to be important for heteromeric ACCase enzyme activity. The leucine residue is genomically encoded in a number of

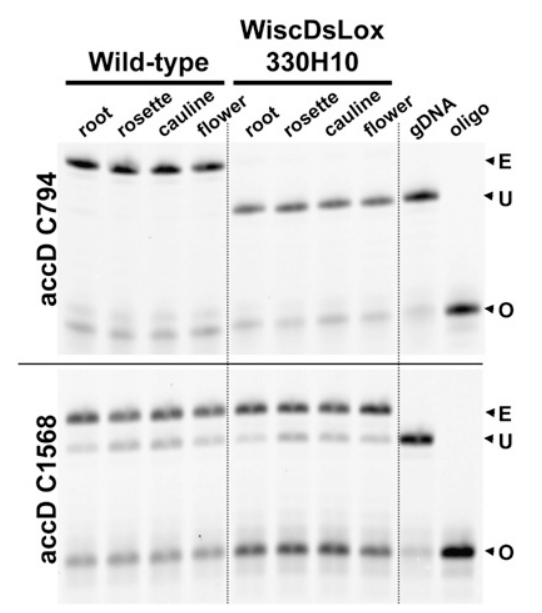

FIGURE 7. No tissue-specific variation in editing extent in $a c c D$ sites was detected in four tissues of wild-type and mutant plants. Editing of accD C794 and C1568 sites was assayed in RNA extracted from four different tissues of wild-type Columbia and WiscDsLox $330 \mathrm{H} 10$ homozygous mutant plants. Extension product sizes as in Figure 4. 


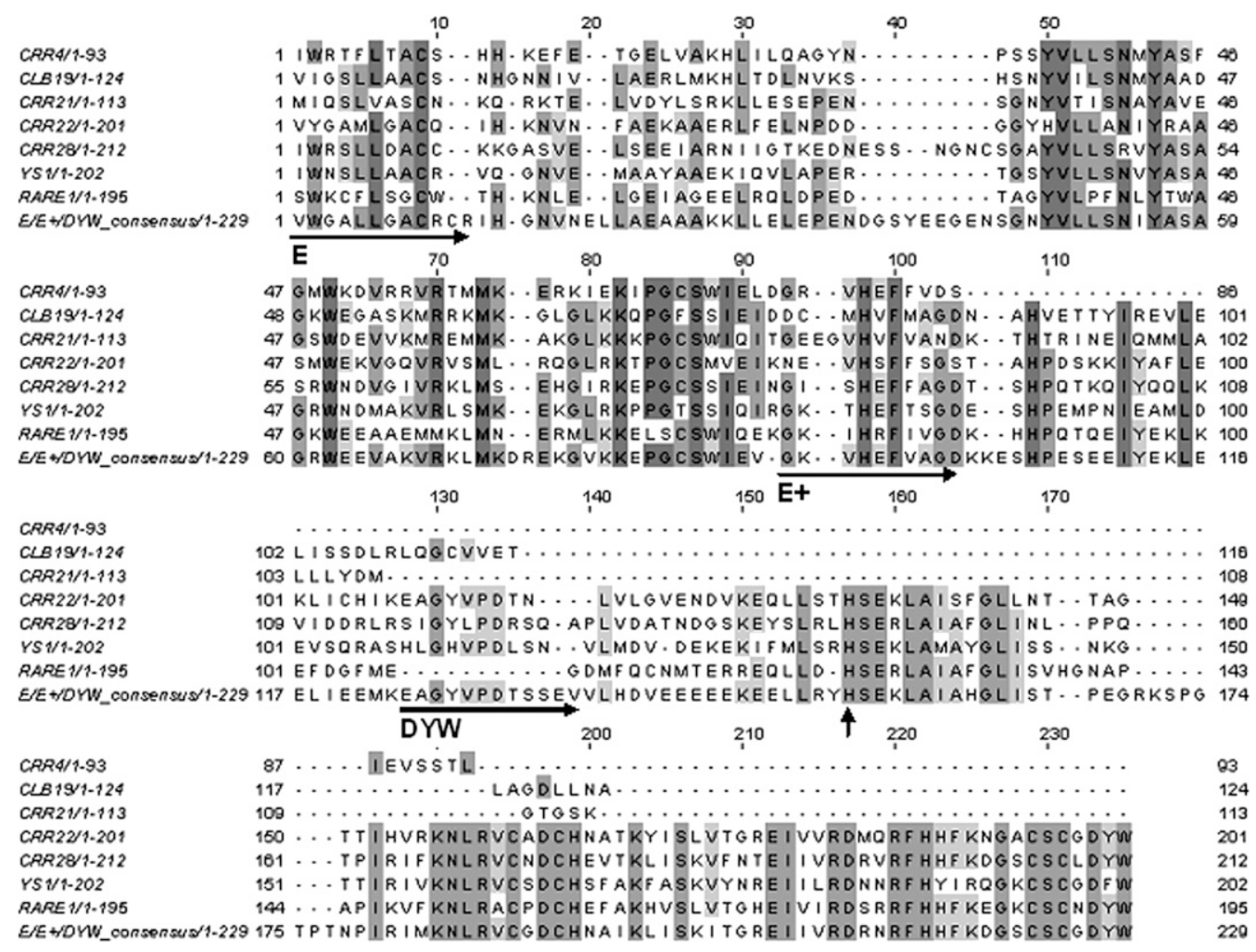

FIGURE 8. Comparative alignments of the C-terminal regions (E-to-DYW domain) of seven PPR-containing proteins (CRR4, CRR21, CLB19, CRR22, CRR28, YS1, and RARE1) that are known to influence chloroplast RNA C-to-U editing. The C-terminal domains (E-to-DYW) of published protein model sequences and the consensus E-to-DYW sequence (Lurin et al. 2004) were aligned using T-Coffee v. 5.05 and are presented using Jalview v.2 (Waterhouse et al. 2009). Intensity of shading reflects the percentage of sequence identity. The arrows indicate the beginning of the consensus of the E, E+, and DYW domains. The vertical arrow indicates the beginning of the highly conserved region, which continues to the $\mathrm{C}$ terminus, of the DYW domain.

plant species and is also present in Escherichia coli (Fig. 9). In the three-dimensional structure of the E. coli subunit, the leucine codon is present at the subunit interface (Bilder et al. 2006; Yura and Go 2008), and thus may affect multimeric enzyme integrity. When tobacco plants were transformed with a construct designed to disrupt the $a c c D$ gene, homoplasmic plastid transformants could not be obtained, evidently because loss of all wild-type copies of $a c c D$ would be lethal. Tobacco plants selected to carry some defective $a c c D$ genes exhibited severe leaf development defects (Kode et al. 2005). Furthermore, accD transcription and protein accumulation is evidently important in the specialized type of chloroplasts found in tomato fruit, where photosynthetic genes are down-regulated but $a c c D$ expression is up-regulated (Kahlau and Bock 2008).

When the wild-type forms of the two subunits of the pea carboxyltransferase were expressed in E. coli with a His tag on the $\alpha$ subunit and purified on a nickel column, the protein complex exhibited carboxyltransferase and ACCase activity (Kozaki et al. 2000). Expression in E. coli of a version of the $a c c D$ gene that would encode a $\beta$ subunit corresponding to the unedited transcript resulted in neither carboxyltransferase nor ACCase activity. Furthermore, the mutant subunit exhibited different solubility properties (Sasaki et al. 2001). In fact, the pea ACCase study is one of the few that are often cited to demonstrate an important biological role of chloroplast RNA editing. Most evidence for the importance of RNA editing in plant organelle protein function does not result from direct biochemical studies, but instead from observations that a particular amino acid is highly conserved in comparison to the amino acid that would be encoded by an unedited transcript. The predicted pea and Arabidopsis proteins differ considerably in the $\mathrm{N}$-terminal portion of the $\beta$ carboxyltransferase prior to the zinc-binding domain, and beginning at 24 codons after the edited codon, pea exhibits a 112-codon insertion relative to Arabidopsis (Supplemental Fig. S5). The Arabidopsis protein therefore varies considerably from its pea ortholog that was tested by heterologous expression by Sasaki et al. (2001). It is possible that the diverged sequence allows some function of the Arabidopsis protein despite the presence of a serine at residue 265.

Another possibility is that the Arabidopsis plastid ACCase is not required for plant development because of the 


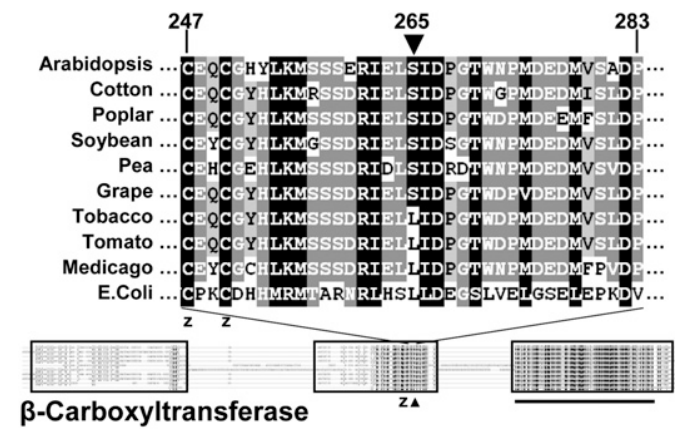

FIGURE 9. Conservation of protein sequences near the amino acid in the $\beta$ carboxyltransferase subunit of ACCase affected by editing of C794. Alignment of $\beta$ carboxyltransferase protein sequences from nine plant and one bacterial species. Conserved regions are boxed. Alignment was performed by T-COFFEE and viewed with GeneDoc. GenBank accessions containing the accD gene from each species used are: AP000423, DQ345959, EF489041, DQ317523, X56315, DQ424856, Z00044, AM087200, AC093544, and NC_000913. Upper panel: amino acid sequences of the central conserved region containing the residue affected by RNA editing (arrow). Conserved cysteinyl zinc ligands (Bilder et al. 2006) are indicated by $(z)$. Numbers indicate residues in the Arabidopsis sequence. Lower panel: graphical depiction of ACCase $\beta$ carboxyltransferase subunit protein alignment. An enlarged version of the complete alignment can be viewed in Supplemental Figure S5. The conserved carboxyl transferase domain is underlined; arrow and $\mathrm{z}$ symbols are as in the upper panel.

presence of a homomeric eukaryotic-type ACCase in the plastid, as is the case in rice and other grasses that lack the heteromeric bacterial-type ACCase (Konishi et al. 1996). The Arabidopsis nuclear genome exhibits two genes expected to encode eukaryotic-type homomeric ACCases, $A C C 1$ and ACC2. Disruption of the ACC1 gene results in embryo lethality (Baud et al. 2003). While the ACC1 protein has been shown to function in the cytosol, both Predotar and TargetP predict a plastid transit sequence at the $\mathrm{N}$ terminus of Arabidopsis ACC2. In the related species Brassica napus, the $\mathrm{N}$ terminus of the ACC2 protein was shown to target GFP to tobacco chloroplasts (Schulte et al. 1997).

While the current report is focused on RNA metabolism, it will be worthwhile in future studies to study the activity and accumulation of the heteromeric ACCase in rare 1 mutants, as well as more rigorously examine the growth and development of rare 1 mutant plants under a variety of environmental conditions. If the unedited $a c c D$ transcript results in a dysfunctional protein, fatty acid content of vegetative and reproductive tissues of mutants may be altered. Assays of the Arabidopsis enzyme in vivo and in vitro will reveal whether or not Arabidopsis can tolerate the presence of a S265 in the $\beta$ carboxyltransferase subunit of ACCase, unlike the pea enzyme. Future work will reveal whether the homomeric ACCase(s) or other enzymes that may be present in Arabidopsis may be able to compensate for a heteromeric ACCase containing $\beta$ carboxyltransferase translated from unedited transcripts.

\section{MATERIALS AND METHODS}

\section{Plant growth}

A. thaliana ecotype Columbia was grown in 16 -h light/8-h dark under full-spectrum fluorescent lights in a growth room at $26^{\circ} \mathrm{C}$ for use in VIGS experiments. For all other experiments, plants were grown in 15-h light/9-h dark under metal halide lamps at $26^{\circ} \mathrm{C}$.

\section{Virus-induced gene silencing}

Silencing fragments were amplified by PCR using the gene sequence tag (GST) primers (Supplemental Table S1) designated by the CATMA database (Crowe et al. 2003), using Taq PCR Mastermix (Qiagen). PCR products were cloned using pCR8/ GW/TOPO TA Cloning Kit (Invitrogen), and plasmid DNA was isolated from spectinomycin-resistant transformants using the PureLink Quick Plasmid Miniprep Kit (Invitrogen).

To generate the silencing vector pTRV2GFPGW, we first inserted Gateway Reading Frame A (Gateway Conversion System, Invitrogen) at the SmaI site of pYL170 (Burch-Smith et al. 2006), and subsequently inserted a 200-bp fragment of the mGFP4 (Haseloff et al. 1997) gene between SacI and XbaI. The mGFP4 fragment was amplified using the SacI-mGFP4 and XbaImGFP4 primers listed in Supplemental Table S1, cloned into pCR8/GW/TOPO, cut from vector backbone, and gel purified prior to ligation to the pYL170-Gateway derivative. Recombination of the pCR8 entry clones with pTRV2GFPGW using LR Clonase II enzyme mix (Invitrogen) produced the final silencing constructs, which were electrotransformed into E. coli $\mathrm{DH} \alpha$, then purified plasmid DNA was subcloned into Agrobacterium tumefaciens GV3101. Agrobacterium strains were maintained on LB agar containing $50 \mu \mathrm{g} / \mathrm{mL}$ kanamycin and $100 \mu \mathrm{g} / \mathrm{mL}$ rifampicin.

Ecotype Col-0 mGFP5-expressing Arabidopsis kindly provided by Dominique Roberston (Noth Carolina State University) (Turnage et al. 2002), were used for visual screening of GFP expression or silencing under long wave UV irradiation using a BLAK-RAY Model B 100 AP lamp (UVP). Plant growth conditions and Agro-inoculation of Arabidopsis leaves were as described in Burch-Smith et al. (2006).

\section{RNA isolation and cDNA synthesis}

Two weeks after inoculation, plants were screened for cosilencing of GFP, and individual silenced rosette leaves were harvested and flash-frozen in liquid nitrogen. Total leaf RNA was isolated using Trizol reagent (Invitrogen), and CDNA was synthesized using the Sensiscript Reverse Transcriptase Kit (Qiagen) and random nonamer primers. Fragments of 18 chloroplast transcripts containing all known Arabidopsis editing sites were amplified using the primers listed in Supplemental Table S1. For semiquantiative RT-PCR analysis, RNA was primed with random nonamers or At5g13270_RT_R for production of ACTIN or RARE1 cDNA; PCR was performed with Actin_F and Actin_R to generate the actin product, and At5g13270_RTPCR_F and At5g13270_RTPCR_R to generate the RARE1 product. Aliquots of PCR reactions were removed at cycles indicated (Fig. 5), and electrophoresed in 1\% agarose gels. 


\section{Poisoned primer extension}

RNA was isolated from Arabidopsis tissues and analyzed by PPE as previously described (Hayes and Hanson 2007a). Primers used for PPE are listed in Supplemental Table S1, as either PPE_C or PPE_G, denoting whether the sequencing reactions contained ddCTP or ddGTP, respectively. PPE reactions were performed as in Hegeman et al. (2005), except for PPE oligonucleotides with the 5' Hexachlorofluorecein (HEX) tag modification as in Roberson and Rosenthal (2006), purchased from IDT, in which case 0.5 pmol of fluorescently labeled primer was used in place of radiolabeled primer. HEX tagged extension products were detected by a Typhoon 9400 imager (GE Healthcare), using the $555 \mathrm{~nm}$ bandpass-20 filter, excitation at $532 \mathrm{~nm}$, and with the photomultiplier tube voltage set at 600 .

\section{Identification of T-DNA insertional mutants}

Line WiscDsLox330H10 (stock CS851454) with a T-DNA insertion mapped within the coding region of At5g13270, was obtained from the Arabidopsis Biological Resource Center (ABRC [The Ohio State University]). A segregating population was grown on soil and genotyped using the primers listed in Supplemental Table S1, where primers At5g13270_5'_+1726 and At5g13270_3' +2328 amplify the wild-type allele, and At5g13270_5'_+1726 and WiscLB amplify the mutant allele. WS-4 Line FLAG_424E06 was obtained from the INRA Versaille T-DNA collection (Samson et al. 2002). The insertional allele was verified by primers At5g13270_5'_-468 and LB4 and primers At5g13270_5'_-468 and At5g13270_3'_+123 amplified the wild-type allele (Supplemental Table S1). PCR was performed with BioMix Red (Bioline). Line 167A04 was obtained from GABI-Kat II (Rosso et al. 2003), and genotyped using primers At5g13270_5'_-468 and At5g13270_ V_F to amplify the wild-type allele, and GABI-LB and At5g13270_ V_R for the insertional allele.

\section{Confocal microscopy}

A Leica DMRE-7 (SDK) microscope with a TCS-SP2 confocal scanning head (Leica Microsystems Inc.) and a $63 \times$ water immersion objective was used to collect confocal laser scanning images of chloroplasts in wild-type and mutant plants. Chlorophyll fluorescence was excited with $633 \mathrm{~nm}$ light and collected between 660 and $700 \mathrm{~nm}$ in order to make projections of Z-series.

\section{Bioinformatic analysis}

The PlantRBP (http://plantrbp.uoregon.edu/) was consulted to identify putative orthologous groups. Prediction of chloroplast transit sequences was performed with Predotar v. 1.03 (Small et al. 2004) [http://urgi.versailles.inra.fr/predotar/predotar.html] and TargetP 1.1 (Emanuelsson et al. 2007) [http://www.cbs.dtu.dk/ services/TargetP/]. Sequences were translated and aligned using $\mathrm{T}$ Coffee Version_7.44 [http://www.tcoffee.org] (Notredame et al. 2000). Alignments and residue characteristics were displayed using GeneDoc [http://www.psc.edu/biomed/genedoc] or Jalview v.2 (Waterhouse et al. 2009). Information about protein motifs was obtained from Pfam (http://pfam.sanger.ac.uk/).

\section{SUPPLEMENTAL MATERIAL}

Supplemental material can be found at http://www.rnajournal.org.

\section{ACKNOWLEDGMENTS}

This research was supported by NSF MCB Grant 0716888 and NSF DBI 9975838 to M.R.H. We thank Lin Lin for performing PPE, and S.P. Dinesh-Kumar and D. Robertson for providing valuable research materials.

Received December 24, 2008; accepted March 11, 2009.

\section{REFERENCES}

Baud, S., Guyon, V., Kronenberger, J., Wuilleme, S., Miquel, M., Caboche, M., Lepiniec, L., and Rochat, C. 2003. Multifunctional acetyl-CoA carboxylase 1 is essential for very long chain fatty acid elongation and embryo development in Arabidopsis. Plant J. 33: 75-86.

Bentolila, S., Chateigner-Boutin, A.L., and Hanson, M.R. 2005. Ecotype allelic variation in C-to-U editing extent of a mitochondrial transcript identifies RNA-editing quantitative trait loci in Arabidopsis. Plant Physiol. 139: 2006-2016.

Bentolila, S., Elliott, L.E., and Hanson, M.R. 2008. Genetic architecture of mitochondrial editing in Arabidopsis thaliana. Genetics 178: 1693-1708.

Bilder, P., Lightle, S., Bainbridge, G., Ohren, J., Finzel, B., Sun, F., Holley, S., Al-Kassim, L., Spessard, C., Melnick, M., et al. 2006. The structure of the carboxyltransferase component of acetyl-coA carboxylase reveals a zinc-binding motif unique to the bacterial enzyme. Biochemistry 45: 1712-1722.

Bock, R. 2000. Sense from nonsense: How the genetic information of chloroplasts is altered by RNA editing. Biochimie 82: 549-557.

Burch-Smith, T.M., Schiff, M., Liu, Y., and Dinesh-Kumar, S.P. 2006. Efficient virus-induced gene silencing in Arabidopsis. Plant Physiol. 142: $21-27$.

Chateigner-Boutin, A.L. and Hanson, M.R. 2002. Cross-competition in transgenic chloroplasts expressing single editing sites reveals shared cis elements. Mol. Cell. Biol. 22: 8448-8456.

Chateigner-Boutin, A.L. and Small, I. 2007. A rapid high-throughput method for the detection and quantification of RNA editing based on high-resolution melting of amplicons. Nucleic Acids Res. 35: e114. doi: 10.1093/nar/gkm640.

Chateigner-Boutin, A.L., Ramos-Vega, M., Guevara-Garcia, A., Andres, C., de la Luz Gutierrez-Nava, M., Cantero, A., Delannoy, E., Jimenez, L.F., Lurin, C., Small, I., et al. 2008. CLB19, a pentatricopeptide repeat protein required for editing of rpoA and clpP chloroplast transcripts. Plant J. 56: 590-602.

Chaudhuri, S. and Maliga, P. 1996. Sequences directing C-to-U editing of the plastid $p s b L$ mRNA are located within a 22 nucleotide segment spanning the editing site. EMBO J. 15: 59585964.

Corneille, S., Lutz, K., and Maliga, P. 2000. Conservation of RNA editing between rice and maize plastids: Are most editing events dispensable? Mol. Gen. Genet. 264: 419-424.

Covello, P.S. and Gray, M.W. 1993. On the evolution of RNA editing. Trends Genet. 9: 265-268.

Crowe, M.L., Serizet, C., Thareau, V., Aubourg, S., Rouze, P., Hilson, P., Beynon, J., Weisbeek, P., van Hummelen, P., Reymond, P., et al. 2003. CATMA: A complete Arabidopsis GST database. Nucleic Acids Res. 31: 156-158.

Emanuelsson, O., Brunak, S., von Heijne, G., and Nielsen, H. 2007. Locating proteins in the cell using TargetP, SignalP, and related tools. Nat. Protocols 2: 953-971.

Gualberto, J.M., Lamattina, L., Bonnard, G., Weil, J.H., and Grienenberger, J.M. 1989. RNA editing in wheat mitochondria results in the conservation of protein sequences. Nature 341: 660662.

Hanson, M.R., Sutton, C.A., and Lu, B. 1996. Plant organelle gene expression: Altered by RNA editing. Trends Plant Sci. 1: 57-64. 
Haseloff, J., Siemering, K.R., Prasher, D.C., and Hodge, S. 1997. Removal of a cryptic intron and subcellular localization of green fluorescent protein are required to mark transgenic Arabidopsis plants brightly. Proc. Natl. Acad. Sci. 94: 2122-2127.

Hashimoto, M., Endo, T., Peltier, G., Tasaka, M., and Shikanai, T. 2003. A nucleus-encoded factor, CRR2, is essential for the expression of chloroplast $n d h B$ in Arabidopsis. Plant J. 36: 541-549.

Hayes, M.L. and Hanson, M.R. 2007a. Assay of editing of exogenous RNAs in chloroplast extracts of Arabidopsis, maize, pea, and tobacco. Methods Enzymol. 424: 459-482.

Hayes, M.L. and Hanson, M.R. 2007b. Identification of a sequence motif critical for editing of a tobacco chloroplast transcript. RNA 13: $281-288$

Hayes, M.L. and Hanson, M.R. 2008. High conservation of a $5^{\prime}$ element required for RNA editing of a $\mathrm{C}$ target in chloroplast psbE transcripts. J. Mol. Evol. 67: 233-245.

Hegeman, C.E., Hayes, M.L., and Hanson, M.R. 2005. Substrate and cofactor requirements for RNA editing of chloroplast transcripts in Arabidopsis in vitro. Plant J. 42: 124-132.

Heller, W.P., Hayes, M.L., and Hanson, M.R. 2008. Crosscompetition in editing of chloroplast RNA transcripts in vitro implicates sharing of trans-factors between different C targets. J. Biol. Chem. 283: 7314-7319.

Hirose, T. and Sugiura, M. 2001. Involvement of a site-specific transacting factor and a common RNA-binding protein in the editing of chloroplast mRNAs: Development of a chloroplast in vitro RNA editing system. $E M B O J$. 20: 1144-1152.

Kahlau, S., Aspinall, S., Gray, J.C., and Bock, R. 2006. Sequence of the tomato chloroplast DNA and evolutionary comparison of solanaceous plastid genomes. J. Mol. Evol. 63: 194-207.

Kahlau, S. and Bock, R. 2008. Plastid transcriptomics and translatomics of tomato fruit development and chloroplast-to-chromoplast differentiation: Chromoplast gene expression largely serves the production of a single protein. Plant Cell 20: $856-874$

Kode, V., Mudd, E.A., Iamtham, S., and Day, A. 2005. The tobacco plastid $a c c D$ gene is essential and is required for leaf development. Plant J. 44: 237-244.

Konishi, T., Shinohara, K., Yamada, K., and Sasaki, Y. 1996. AcetylCoA carboxylase in higher plants: Most plants other than Gramineae have both the prokaryotic and the eukaryotic forms of this enzyme. Plant Cell Physiol. 37: 117-122.

Kotera, E., Tasaka, M., and Shikanai, T. 2005. A pentatricopeptide repeat protein is essential for RNA editing in chloroplasts. Nature 433: 326-330.

Kozaki, A., Kamada, K., Nagano, Y., Iguchi, H., and Sasaki, Y. 2000. Recombinant carboxyltransferase responsive to redox of pea plastidic acetyl-CoA carboxylase. J. Biol. Chem. 275: 1070210708

Kudla, J., Igloi, G.L., Metzlaff, M., Hagemann, R., and Kossel, H. 1992. RNA editing in tobacco chloroplasts leads to the formation of a translatable $p s b L$ mRNA by a C-to-U substitution within the initiation codon. EMBO J. 11: 1099-1103.

Lurin, C., Andres, C., Aubourg, S., Bellaoui, M., Bitton, F., Bruyere, C., Caboche, M., Debast, C., Gualberto, J., Hoffmann, B., et al. 2004. Genome-wide analysis of Arabidopsis pentatricopeptide repeat proteins reveals their essential role in organelle biogenesis. Plant Cell 16: 2089-2103.

Nakamura, T. and Sugita, M. 2008. A conserved DYW domain of the pentatricopeptide repeat protein possesses a novel endoribonuclease activity. FEBS Lett. 582: 4163-4168.

Notredame, C., Higgins, D.G., and Heringa, J. 2000. T-Coffee: A novel method for fast and accurate multiple sequence alignment. J. Mol. Biol. 302: 205-217.

Okuda, K., Nakamura, T., Sugita, M., Shimizu, T., and Shikanai, T. 2006. A pentatricopeptide repeat protein is a site recognition factor in chloroplast RNA editing. J. Biol. Chem. 281: 3766137667.

Okuda, K., Myouga, F., Motohashi, R., Shinozaki, K., and Shikanai, T. 2007. Conserved domain structure of pentatricopeptide repeat proteins involved in chloroplast RNA editing. Proc. Natl. Acad. Sci. 104: $8178-8183$.

Okuda, K., Chateigner-Boutin, A.L., Nakamura, T., Delannoy, E., Sugita, M., Myouga, F., Motohashi, R., Shinozaki, K., Small, I., and Shikanai, T. 2009. Pentatricopeptide repeat proteins with the DYW motif have distinct molecular functions in RNA Editing and RNA cleavage in Arabidopsis chloroplasts. Plant Cell 21: 146-156.

Peeters, N.M. and Hanson, M.R. 2002. Transcript abundance supercedes editing efficiency as a factor in developmental variation of chloroplast gene expression. RNA 8: 497-511.

Reed, M.L., Peeters, N.M., and Hanson, M.R. 2001. A single alteration 20 nt $5^{\prime}$ to an editing target inhibits chloroplast RNA editing in vivo. Nucleic Acids Res. 29: 1507-1513.

Roberson, L.M. and Rosenthal, J.J. 2006. An accurate fluorescent assay for quantifying the extent of RNA editing. RNA 12: 1907-1912.

Rosso, M.G., Li, Y., Strizhov, N., Reiss, B., Dekker, K., and Weisshaar, B. 2003. An Arabidopsis thaliana T-DNA mutagenized population (GABI-Kat) for flanking sequence tag-based reverse genetics. Plant Mol. Biol. 53: 247-259.

Salone, V., Rudinger, M., Polsakiewicz, M., Hoffmann, B., GrothMalonek, M., Szurek, B., Small, I., Knoop, V., and Lurin, C. 2007. A hypothesis on the identification of the editing enzyme in plant organelles. FEBS Lett. 581: 4132-4138.

Samson, F., Brunaud, V., Balzergue, S., Dubreucq, B., Lepiniec, L., Pelletier, G., Caboche, M., and Lecharny, A. 2002. FLAGdb/FST: A database of mapped flanking insertion sites (FSTs) of Arabidopsis thaliana T-DNA transformants. Nucleic Acids Res. 30: 94-97.

Sasaki, Y., Kozaki, A., Ohmori, A., Iguchi, H., and Nagano, Y. 2001. Chloroplast RNA editing required for functional acetyl-CoA carboxylase in plants. J. Biol. Chem. 276: 3937-3940.

Schmitz-Linneweber, C. and Small, I. 2008. Pentatricopeptide repeat proteins: A socket set for organelle gene expression. Trends Plant Sci. 13: 663-670.

Schulte, W., Topfer, R., Stracke, R., Schell, J., and Martini, N. 1997. Multi-functional acetyl-CoA carboxylase from Brassica napus is encoded by a multi-gene family: Indication for plastidic localization of at least one isoform. Proc. Natl. Acad. Sci. 94: 3465-3470.

Shikanai, T. 2006. RNA editing in plant organelles: Machinery, physiological function, and evolution. Cell. Mol. Life Sci. 63: 698-708.

Small, I.D. and Peeters, N. 2000. The PPR motif-A TPR-related motif prevalent in plant organellar proteins. Trends Biochem. Sci. 25: 46-47.

Small, I., Peeters, N., Legeai, F., and Lurin, C. 2004. Predotar: A tool for rapidly screening proteomes for N-terminal targeting sequences. Proteomics 4: 1581-1590.

Tillich, M., Funk, H.T., Schmitz-Linneweber, C., Poltnigg, P., Sabater, B., Martin, M., and Maier, R.M. 2005. Editing of plastid RNA in Arabidopsis thaliana ecotypes. Plant J. 43: 708-715.

Tillich, M., Lehwark, P., Morton, B.R., and Maier, U.G. 2006. The evolution of chloroplast RNA editing. Mol. Biol. Evol. 23: 19121921.

Tsudzuki, T., Wakasugi, T., and Sugiura, M. 2001. Comparative analysis of RNA editing sites in higher plant chloroplasts. J. Mol. Evol. 53: 327-332.

Turnage, M.A., Muangsan, N., Peele, C.G., and Robertson, D. 2002. Geminivirus-based vectors for gene silencing in Arabidopsis. Plant J. 30: 107-114.

Uyttewaal, M., Mireau, H., Rurek, M., Hammani, K., Arnal, N., Quadrado, M., and Giege, P. 2008. PPR336 is associated with polysomes in plant mitochondria. J. Mol. Biol. 375: 626-636.

van der Merwe, J.A., Takenaka, M., Neuwirt, J., Verbitskiy, D., and Brennicke, A. 2006. RNA editing sites in plant mitochondria can share cis-elements. FEBS Lett. 580: 268-272.

Walker, N.S., Stiffler, N., and Barkan, A. 2007. POGs/PlantRBP: A resource for comparative genomics in plants. Nucleic Acids Res. 35: D852-D856.

Waterhouse, A.M., Procter, J.B., Martin, D.M.A., Clamp, M., and Barton, G.J. 2009. Jalview Version 2-A multiple sequence 
alignment editor and analysis workbench. Bioinformatics (in press). doi: 10.1093/bioinformatics/btp033.

Wintz, H. and Hanson, M.R. 1991. A termination codon is created by RNA editing in the petunia atp9 transcript. Curr. Genet. 19: 61-64.

Woody, S.T., Austin-Phillips, S., Amasino, R.M., and Krysan, P.J. 2007. The WiscDsLox T-DNA collection: An Arabidopsis community resource generated by using an improved high-throughput T-DNA sequencing pipeline. J. Plant Res. 120: 157-165.

Yura, K. and Go, M. 2008. Correlation between amino acid residues converted by RNA editing and functional residues in protein three-dimensional structures in plant organelles. BMC Plant Biol. 8: 79 .
Zehrmann, A., van der Merwe, J.A., Verbitskiy, D., Brennicke, A., and Takenaka, M. 2008. Seven large variations in the extent of RNA editing in plant mitochondria between three ecotypes of Arabidopsis thaliana. Mitochondrion 8: 319-327.

Zhou, W., Cheng, Y., Yap, A., Chateigner-Boutin, A.L., Delannoy, E., Hammani, K., Small, I., and Huang, J. 2009. The Arabidopsis gene YS1 encoding a DYW protein is required for editing of $r p o B$ transcripts and the rapid development of chloroplasts during early growth. Plant J. 58: 82-96.

Zimmermann, P., Hirsch-Hoffmann, M., Hennig, L., and Gruissem, W. 2004. GENEVESTIGATOR. Arabidopsis microarray database and analysis toolbox. Plant Physiol. 136: 2621-2632. 

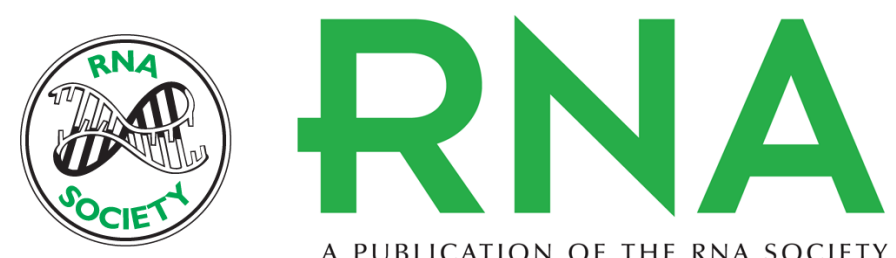

A PUBLICATION OF THE RNA SOCIETY

\section{A comparative genomics approach identifies a PPR-DYW protein that is essential for C-to-U editing of the Arabidopsis chloroplast accD transcript}

John C. Robbins, Wade P. Heller and Maureen R. Hanson

RNA 2009 15: 1142-1153 originally published online April 24, 2009

Access the most recent version at doi:10.1261/rna.1533909

Supplemental http://rnajournal.cshlp.org/content/suppl/2009/04/27/rna.1533909.DC1

Material

References This article cites 63 articles, 19 of which can be accessed free at:

http://rnajournal.cshlp.org/content/15/6/1142.full.html\#ref-list-1

License

Email Alerting Receive free email alerts when new articles cite this article - sign up in the box at the Service top right corner of the article or click here. 